\title{
The Application of Entransy Dissipation Theory on the Performance Analysis of an Irreversible Atkinson Cycle
}

\author{
Govind Maheshwari, Sumer Singh Patel* \\ Department of Mechanical Engineering, Institute of Engineering and Technology, \\ Devi Ahilya University, Indore, Madhya Pradesh 452017, India \\ *Corresponding Author: patelsumer@gmail.com
}

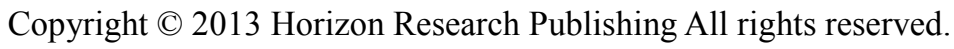

\begin{abstract}
Several techniques on the Second Law of Thermodynamics have been used in the past for the analysis of Air standard Cycles. The terms used for these techniques include irreversibility analysis, entropy generation minimization, exergy analysis and thermodynamic efficiency. Entransy is a recently developed concept reflecting the heat transfer potential, rather than the ability to convert heat to work. This paper extends this concept to optimize thermodynamic processes of an irreversible Atkinson cycle. The entransy balance equation of thermodynamic processes is introduced, with which the concept of entransy dissipation is developed. For the irreversible Atkinson cycle where the working fluid is heated by the streams with prescribed inlet temperatures and specific capacity flow rates, it is found that the maximum entransy dissipation leads to the maximum output work, which is the maximum principle of entransy dissipation in thermodynamic processes. At the same time, it is found that minimum entropy generation alone could not describe change of the output work for the Atkinson cycle. The operation parameters are optimized for evaluating the maximum output work of Atkinson cycle by incorporating maximum entransy dissipation and minimum entropy generation when both, entransy dissipation and entropy generation, are induced by dumping the used streams into the environment is considered.
\end{abstract}

Keywords Entransy Dissipation, Entropy Generation, Irreversible Atkinson Cycle, Maximum Output Work, Environment

\section{Introduction}

The Atkinson cycle is named after its inventor James Atkinson in 1882 Pulkrabek [1]. As the worldwide energy crisis is becoming more and more serious, effective energy utilization and exchange are receiving more and more attention. Considering that nearly $80 \%$ of the total energy consumption is related to heat transfer Chen Q [2]. The improvement of heat transfer is of great significance to reduce energy consumption. A series of achievements has been made, since finite-time thermodynamics was used to analyze and optimize the performance of real thermodynamic processes, devices and cycles Bejan [3], Chen L [4], Ge Y [5], Lin JC [6], I. Prigogine [7] . A. Bejan [8-9] developed the entropy generation minimization (EGM) approach in thermodynamic optimization. The total entropy production rate denoted by $\mathrm{S}_{\mathrm{gen}}$ is the sum of entropy production associated with heat conduction and fluid friction. However, among all the variational principles in thermodynamics, Prigogine's minimum entropy generation principle is still the most debated one V. Bertola [10]. Accordingly the entropy generation minimization approach, widely applied to modeling and optimization of thermal system that owe their thermodynamics imperfection to heat transfer, mass transfer, and fluid flow irreversibility's, demonstrates some inconsistencies and paradoxes in the application of thermodynamic system .This is because the focus of the entropy generation minimization is on the heatwork conversion processes, while in thermodynamic cycles the rate and efficiency of heat transfer are more concerned. A. Bejan [11] related the best heat transfer process to the minimum entropy generation. The minimum principle of entropy generation may be not always applicable to heat transfer optimization.

Nomenclature

C heat capacity flow rate (WK-1)

$C_{P}$ heat capacity flow rate at constant pressure (WK-1)

$C_{V}$ heat capacity flow rate at constant volume (WK-1)

$G_{\text {dis }}$ entransy dissipation not induced by environment

(WK)

$G_{d i s, e}$ entransy dissipation induced by environment (WK)

$Q \quad$ heat transfer rate $(\mathrm{W})$

$S_{g}$ entropy generation not induced by environment (WK-1) 
$S_{g, e} \quad$ entropy generation induced by environment (WK-1)

$T \quad$ temperature (K)

W output work (W)

Greek symbols

$\varepsilon \quad$ effectiveness of heat exchanger

$\gamma$ reversible adiabatic index

Subscripts

$H \quad$ hot fluid

in inlet

$L \quad$ cold fluid

max maximum

min minimum

out outlet

For this purpose, Guo et al [12] introduced a new physical quantity, entransy that describes the heat transfer ability by the analogy between heat and electrical conduction. For body whose internal energy is $U$ and temperature is $T$, its entransy is defined as,

$$
G=\frac{1}{2} U T
$$

Cheng et al. proved that this concept could be used to describe the irreversibility of heat transfer. X.T. Cheng [13] developed a microscopic expression of entransy for a monatomic ideal gas system. X.G. Liang [14] related the entransy to the microstate number and indicated the microscopic physical meaning of entransy to some extent. Guo et al derived the minimum entransy dissipation principle for prescribed heat flux boundary conditions and the maximum entransy dissipation principle for prescribed temperature boundary Conditions. These two principles are referred to as the extreme entransy dissipation principle. Furthermore, Guo et al defined an equivalent thermal resistance of the system based on the entransy dissipation and heat flux. Then, the extreme entransy dissipation principle is equivalent to the minimum thermal resistance principle that is much easier for understanding. These principles are used to optimize heat conduction H.Y. Zhu [15], Z.H. Xie [16], Q.H. Xiao [17]; heat convection Q. Chen [18], Q. Chen [19], J. Wu [20]; thermal radiation J. Wu [21], X.T. Cheng [21]; transport networks X.B. Liu [23]. It is found that the maximum entransy dissipation corresponds to the maximum heat transfer rate when the heat transfer temperature difference is prescribed, while the minimum entransy dissipation corresponds to the minimum heat transfer temperature difference when the heat transfer rate is prescribed.

For the design optimization of thermodynamic cycles the entransy theory is also applicable. In the present work, the entransy balance equations for thermodynamic processes of an irreversible Atkinson cycle are introduced and the expressions for entransy dissipation and entropy generation are derived. In addition, the operation parameters are optimized for obtaining maximum output work from an irreversible Atkinson cycle by incorporating principles of maximum entransy dissipation and minimum entropy generation

\section{Thermodynamic Analysis of the Atkinson Cycle with Irreversible Processes}

The Atkinson cycle with irreversible processes is shown in Fig. 1, where $Q_{H}$ is the heat absorbed by the working fluid from the high temperature stream through the counter flow heat exchanger whose number of heat transfer units is $N T U_{H}$, $Q_{L}$ is the heat released to the low temperature fluid through the counter flow heat exchanger with the number of heat transfer units $N T U_{L}$, and the output work is $W$. The heat capacity flow rate, the inlet and outlet temperature of the high temperature stream are $C_{H}, T_{H-\text { in }}$ and $T_{H-o u t}$, respectively, while those of the low temperature stream are $C_{L}, T_{L_{\text {in }}}$ and $T_{L-\text { out }}$ respectively. For the working fluid, the heat capacity flow rate at constant volume is $C_{V}$ and the heat capacity flow rate at constant pressure is $C_{P}$. The temperature of the working fluid is $T_{1}$ at state 1 and it gets increased to $T_{2}$ at state 2 by isentropic compression. The working fluid is heated by the high temperature stream from state 2 to 3 under constant volume and its temperature gets increased to $T_{3}$. The next process is the second isentropic process during which the mechanical work output is obtained and subsequently the temperature of the working fluid decreases to $T_{4}$ at state 4 . Finally, the working fluid is cooled by the low temperature fluid from state 4 to 1 under constant pressure and returns to its initial state.

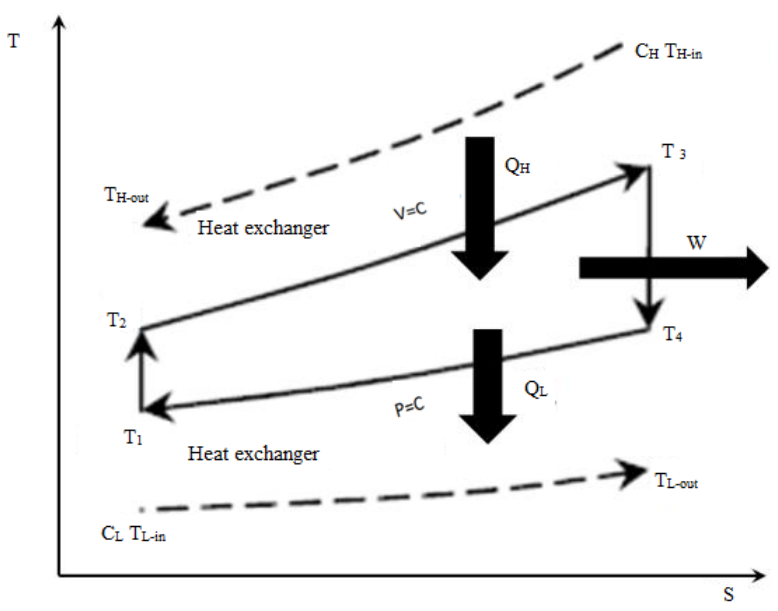

Figure 1. T-s diagram for the cycle model

For the irreversible Atkinson cycle as shown in Fig. 1, the heat transfer rate $\left(\mathrm{Q}_{\mathrm{H}}\right)$ between the working fluid and the high temperature stream is given as :

$$
Q_{H}=C_{H}\left(T_{H-\text { in }}-T_{H-o u t}\right)=C_{H-\min }\left(T_{H-\text { in }}-T_{2}\right) \varepsilon_{H}
$$




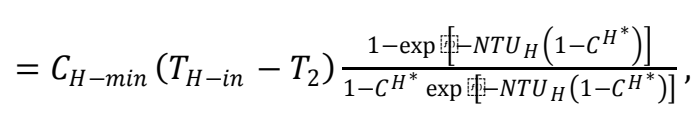

where, $C_{H-\min }$ is the smaller one between $C_{H}$ and $C_{V}, \varepsilon_{H}$ is the effectiveness, and $C^{H^{*}}$ is the capacity ratio of the high temperature stream. One can write the expression of $C^{H^{*}}$ as:

$$
C^{H^{*}}=\frac{\min \left(C_{H}, C_{V}\right)}{\max \left(C_{H}, C_{V}\right)},
$$

Similarly, the heat transfer rate $\left(\mathrm{Q}_{\mathrm{L}}\right)$ between the working fluid and the low temperature stream is

$$
\begin{aligned}
& Q_{L}=C_{L}\left(T_{L-\text { out }}-T_{L-\text { in }}\right)=C_{L-\min }\left(T_{4}-T_{L-\text { in }}\right) \varepsilon_{L} \\
& =C_{L-\min }\left(T_{4}-T_{L-\text { in }}\right) \frac{1-\exp \left[-N T U_{L}\left(1-C^{L^{*}}\right)\right]}{1-C^{L^{*}} \exp \left[-N T U_{L}\left(1-C^{L^{*}}\right)\right]},
\end{aligned}
$$

where $C_{L-\min }$ is the smaller one between $C_{L}$ and $C_{P}, \varepsilon_{L}$ is the effectiveness, and $C^{L^{*}}$ is the capacity ratio of the low temperature stream. One can write the expression of $C^{L^{*}}$ as:

$$
C^{L^{*}}=\frac{\min \left(C_{L}, C_{P}\right)}{\max \left(C_{L}, C_{P}\right)},
$$

Based on Eqs. (2) and (4), one can get:

$$
\begin{gathered}
T_{3}=T_{2}+\frac{Q_{H}}{C_{V}}, \\
T_{1}=T_{4}-\frac{Q_{L}}{C_{P}},
\end{gathered}
$$

The output work rate $(\mathrm{W})$ can be written as:

$$
W=Q_{H}-Q_{L}
$$

For the thermodynamic states 3 and 4 , one can write:

$$
T_{3} v_{3}^{\gamma-1}=T_{4} v_{4}^{\gamma-1},
$$

Equation (9) can be rearranged as:

$$
T_{3}=T_{4} r_{e}^{\gamma-1},
$$

Where, $r_{e}$ is the expansion ratio $=v_{4} / v_{3}$ and $\gamma$ is reversible adiabatic index $={ }^{C_{P}} / C_{V}$

Similarly for thermodynamic states 1 and 2, one can write:

$$
T_{1} v_{1}^{\gamma-1}=T_{2} v_{2}^{\gamma-1}
$$

Equation (11) can be rearranged as:

$$
T_{1}=\frac{T_{2}}{r_{k}{ }^{\gamma-1}},
$$

Where, $r_{k}$ is the compression ratio $=v_{1} / v_{2}$

On combining equation (10) and (12), one can get:

$$
T_{3}=T_{2} * r_{e}^{\gamma} * \frac{1}{r_{k} \gamma}
$$

And consequently,

$$
T_{4}=T_{1} * \frac{r_{e}}{r_{k}}
$$

\subsection{Entropy Generation and Entransy Dissipation when Used Stream is not Dumped into the Environment}

The total entropy generation rate $\left(S_{g}\right)$ in gas-gas heat exchanger, when used stream is not dumped into the environment, can be written as Chen Q [24].

$$
S_{g}=\left(C_{H} \ln \frac{T_{H-o u t}}{T_{H-i n}}+C_{V} \ln \frac{T_{3}}{T_{2}}\right)+\left(C_{L} \ln \frac{T_{L-o u t}}{T_{L-i n}}+C_{P} \ln \frac{T_{1}}{T_{4}}\right),
$$

Equation (15) can be rearranged as:

$$
S_{g}=\left(C_{H} \ln \frac{T_{H-o u t}}{T_{H-\text { in }}}+\frac{C_{P}}{\gamma} \ln \frac{T_{3}}{T_{2}}\right)+\left(C_{L} \ln \frac{T_{L-o u t}}{T_{L-\text { in }}}+C_{P} \ln \frac{T_{1}}{T_{4}}\right),
$$

By using Eqs. (2) and (4), one can get:

$$
\begin{gathered}
T_{H-\text { out }}=T_{H-\text { in }}-\frac{Q_{H}}{C_{H}}, \\
T_{L-\text { out }}=T_{L-\text { in }}+\frac{Q_{L}}{C_{L}},
\end{gathered}
$$

The entransy dissipation $\left(G_{d i s}\right)$, induced by dumping the used stream into the environment is not taken into account, can be calculated as:

$$
G_{\text {dis }}=G_{\text {inlet }}-G_{\text {outlet }},
$$

Where $G_{\text {inlet }}$ is the entransy that flow out of the hot stream and $G_{\text {outlet }}$ is the entransy into the cold stream

For any heat exchanger with one dimensional steady flow, the energy balance equation of the hot fluid can be written as:

$$
C_{H} \frac{d T_{H}(x)}{d x}=-Q(x),
$$

Where $C_{H}$ is the heat capacity flow rate, $Q(x)$ is the heat transfer rate at $x, T_{H}(x)$ is the temperature of the hot fluid at $x$. Multiplying both side of eq. (20) by the hot fluid temperature $T_{H}(x)$, the entransy balance equation of the hot fluid can be written as:

$$
\begin{array}{r}
C_{H} \int_{T_{H-\text { out }}}^{T_{H-i n}} T_{H} d T_{H}=\int Q(x) T_{H}(x) d x, \\
\frac{1}{2} C_{H} T_{H-\text { in }}^{2}-\frac{1}{2} C_{H} T_{H-\text { out }}^{2}=\int Q(x) T_{H}(x) d x,
\end{array}
$$

Similarly, the entransy balance equation of the cold fluid can be written as:

$$
\frac{1}{2} C_{L} T_{L-o u t}^{2}-\frac{1}{2} C_{L} T_{L-\text { in }}^{2}=\int Q(x) T_{L}(x) d x,
$$


Equation (21) and (22) in equation (19), one can get:

$$
G_{\text {dis }}=\left[\frac{1}{2} C_{H} T_{H-\text { in }}^{2}+\frac{1}{2} C_{L} T_{L-\text { in }}^{2}\right]-\left[\frac{1}{2} C_{H} T_{H-\text { out }}^{2}+\frac{1}{2} C_{L} T_{L-o u t}^{2}\right]=\int Q(x)\left[T_{H}(x)-T_{L}(x)\right] d x,
$$

Equation (23) can be rearranged as:

$$
\begin{gathered}
G_{\text {dis }}=G_{\text {inlet }}-G_{\text {outlet }}=\frac{1}{2} C_{H}\left(T_{H-\text { in }}^{2}-T_{H-\text { out }}^{2}\right) \\
-\frac{1}{2} C_{L}\left(T_{L-\text { out }}^{2}-T_{L-\text { in }}^{2}\right)
\end{gathered}
$$

\subsection{Entropy Generation and Entransy Dissipation when Used Stream is Dumped into the Environment}

The total entropy generation rate $\left(S_{g, e}\right)$ in gas-gas heat exchanger when used stream is dumped into the environment can be written as:

$$
\begin{gathered}
S_{g, e}=\left(C_{H} \ln \frac{T_{H-\text { out }}}{T_{H-\text { in }}}+C_{V} \ln \frac{T_{3}}{T_{2}}\right) \\
+\left(C_{L} \ln \frac{T_{L-\text { out }}}{T_{L-\text { in }}}+C_{P} \ln \frac{T_{1}}{T_{4}}\right)+ \\
\frac{Q_{e 1}}{T_{0}}+\frac{Q_{e 2}}{T_{0}},
\end{gathered}
$$

Where $Q_{e 1}$ and $Q_{e 2}$ are the heat exchanges between the used streams and the environment, whose expressions are

$$
\begin{gathered}
Q_{e 1}=C_{H}\left(T_{H-o u t}-T_{0}\right), \\
Q_{e 2}=C_{L}\left(T_{L-\text { out }}-T_{0}\right),
\end{gathered}
$$

Using Equation (26) and (27) in equation (25), one can get:

$$
S_{g, e}=\left(C_{H} \ln \frac{T_{H-\text { out }}}{T_{H-\text { in }}}+C_{V} \ln \frac{T_{3}}{T_{2}}\right)+\left(C_{L} \ln \frac{T_{L-\text { out }}}{T_{L-\text { in }}}+C_{P} \ln \frac{T_{1}}{T_{4}}\right)+\frac{C_{H}\left(T_{H-\text { out }}-T_{0}\right)}{T_{0}}+\frac{C_{L}\left(T_{L-\text { out }}-T_{0}\right)}{T_{0}},
$$

Using Equation (17) and (18) in Equation (28), one can get:

$$
\begin{array}{r}
S_{g, e}=\left(C_{H} \ln \frac{T_{H-\text { out }}}{T_{H-\text { in }}}+C_{V} \ln \frac{T_{3}}{T_{2}}\right) \\
+\left(C_{L} \ln \frac{T_{L-\text { out }}}{T_{L-\text { in }}}+C_{P} \ln \frac{T_{1}}{T_{4}}\right) \\
+\frac{C_{H}\left(T_{H-\text { in }}-\frac{Q_{H}}{C_{H}}-T_{0}\right)}{T_{0}} \\
+\frac{C_{L}\left(T_{L-\text { in }}+\frac{Q_{L}}{C_{L}}-T_{0}\right)}{T_{0}}
\end{array}
$$

Equation (29) can be rearranged as:

$$
S_{g, e}=\left(C_{H} \ln \frac{T_{H-o u t}}{T_{H-\text { in }}}+C_{V} \ln \frac{T_{3}}{T_{2}}\right)+\left(C_{L} \ln \frac{T_{L-o u t}}{T_{L-\text { in }}}+C_{P} \ln \frac{T_{1}}{T_{4}}\right)+\frac{C_{H}\left(T_{H-\text { in }}-T_{0}\right)}{T_{0}}+\frac{C_{L}\left(T_{L-\text { in }}-T_{0}\right)}{T_{0}}-\frac{\left(Q_{H}-Q_{L}\right)}{T_{0}},
$$

Using Equation (8) in Equation (30), one can get:

$$
\begin{gathered}
S_{g, e}=\left(C_{H} \ln \frac{T_{H-\text { out }}}{T_{H-\text { in }}}+C_{V} \ln \frac{T_{3}}{T_{2}}\right) \\
+\left(C_{L} \ln \frac{T_{L-\text { out }}}{T_{L-\text { in }}}+C_{P} \ln \frac{T_{1}}{T_{4}}\right) \\
+\frac{C_{H}\left(T_{H-\text { in }}-T_{0}\right)+C_{L}\left(T_{L-\text { in }}-T_{0}\right)}{T_{0}}-\frac{W}{T_{0}},
\end{gathered}
$$

The entransy dissipation $\left(G_{d i s, e}\right)$, induced by dumping the used stream into the environment is taken into account, can be calculated as:

$$
G_{\text {dis }, e}=G_{\text {inlet }, e}-G_{\text {outlet }, e},
$$


Where $G_{\text {inlet }, e}$ is the entransy that flows out of the hot stream into the environment and $G_{\text {outlet }, e}$ is the entransy of the cold stream into the environment:

$$
\begin{aligned}
G_{\text {inlet }, e}= & \frac{1}{2} C_{H}\left(T_{H-i n}^{2}-T_{0}^{2}\right)+\frac{1}{2} C_{L}\left(T_{L-i n}^{2}-T_{0}^{2}\right), \\
& G_{\text {outlet }, e}=\left(Q_{e 1}+Q_{e 2}\right) T_{0},
\end{aligned}
$$

Using Equation (33) and (34) in equation (32), one can get:

$$
\begin{aligned}
G_{d i s, e} & =\frac{1}{2} C_{H}\left(T_{H-i n}^{2}-T_{0}^{2}\right)+\frac{1}{2} C_{L}\left(T_{L-i n}^{2}-T_{0}^{2}\right)-Q_{e 1} T_{0}-Q_{e 2} T_{0} \\
& =\frac{1}{2} C_{H}\left(T_{H-i n}^{2}-T_{0}^{2}\right)+\frac{1}{2} C_{L}\left(T_{L-i n}^{2}-T_{0}^{2}\right)-\left[Q_{e 1}+Q_{e 2}\right] T_{0},
\end{aligned}
$$

Using Equation (26) and (27) in Equation (35), one can get:

$$
G_{d i s, e}=\frac{1}{2} C_{H}\left(T_{H-\text { in }}^{2}-T_{0}^{2}\right)+\frac{1}{2} C_{L}\left(T_{L-\text { in }}^{2}-T_{0}^{2}\right)-\left[C_{H}\left(T_{H-\text { out }}-T_{0}\right)+C_{L}\left(T_{L-\text { out }}-T_{0}\right)\right] T_{0},
$$

Using Equation (17) and (18) in Equation (36), one can get:

$$
G_{d i s, e}=\frac{1}{2} C_{H}\left(T_{H-i n}^{2}-T_{0}^{2}\right)+\frac{1}{2} C_{L}\left(T_{L-i n}^{2}-T_{0}^{2}\right)-\left[C_{H}\left(T_{H-i n}-\frac{Q_{H}}{C_{H}}-T_{0}\right)+C_{L}\left(T_{L-i n}+\frac{Q_{L}}{C_{L}}-T_{0}\right)\right] T_{0},
$$

Equation (37) can be rearranged as:

$$
G_{d i s, e}=\frac{1}{2} C_{H}\left(T_{H-i n}^{2}-T_{0}^{2}\right)+\frac{1}{2} C_{L}\left(T_{L-i n}^{2}-T_{0}^{2}\right)-C_{H} T_{0}\left(T_{H-i n}-T_{0}\right)-C_{L} T_{0}\left(T_{L-i n}-T_{0}\right)+\left(Q_{H}-Q_{L}\right) T_{0},
$$

Using Equation (8) in Equation (38), one can get:

$$
G_{d i s, e}=\frac{1}{2} C_{H}\left(T_{H-i n}^{2}-T_{0}^{2}\right)+\frac{1}{2} C_{L}\left(T_{L-i n}^{2}-T_{0}^{2}\right)-C_{H} T_{0}\left(T_{H-i n}-T_{0}\right)-C_{L} T_{0}\left(T_{L-i n}-T_{0}\right)+W T_{0},
$$

\section{Results and Discussion}

The derived expressions above are used and plotted in order to compare performance parameters of the Atkinson cycle with $T_{2}$. For the numerical calculations in the present work, the following values are used [25].

$$
C_{H}=3 \mathrm{~W} / \mathrm{K}, C_{L}=2 \mathrm{~W} / \mathrm{K}, \gamma=1.4, r_{k}=8, T_{H-i n}=400 \mathrm{~K}, T_{L-i n}=T_{0}=300 \mathrm{~K}, N T U_{H}=3 \text { and } N T U_{L}=2 .
$$

Variations of the normalised output work, normalised entropy generation and normalised entransy dissipation with different values of $T_{2}$, when the entropy generation and the entransy dissipation induced by dumping the used stream into the environment is not considered, are shown in Fig.2. As can be seen from the figure, values of normalised output work (W/W $(\max )$ ) goes on increasing with $\mathrm{T} 2$ and attains its maximum value at $\mathrm{T} 2=350 \mathrm{~K}$. On the other hand, values of normalised entropy generation $(\mathrm{Sg} / \mathrm{Sg}(\max ))$ and normalised entransy dissipation (Gdis/Gdis $(\max )$ ) go on decreasing with $\mathrm{T} 2$. The normalised entropy generation $(\mathrm{Sg} / \mathrm{Sg}(\max ))$ attains its minimum value at temperature $\mathrm{T} 2>375 \mathrm{~K}$ while normalised entransy dissipation (Gdis/Gdis (max)) has its maximum value at T2 $=325 \mathrm{~K}$. The above observations can also be drawn by evaluating Equations (8), (16) and (24). Hence, the minimum entropy generation and the maximum entransy dissipation both does not correspond to the maximum output work when dumping the used stream into the environment is not considered

Variations of the normalised output work, normalised entropy generation and normalised entransy dissipation with different values of $T_{2}$, when the entropy generation and the entransy dissipation induced by dumping the used stream into the environment is considered, are shown in Fig.3. As can be seen from the figure, values of normalised output work (W/W $(\max ))$ goes on increasing with $\mathrm{T} 2$ and attains its maximum value at $\mathrm{T} 2=350 \mathrm{~K}$. On the other hand, values of normalised entropy generation $(\mathrm{Sg}, \mathrm{e} / \mathrm{Sg}$, e (max)) goes on decreasing and normalised entransy dissipation (Gdis, e/Gdis, e (max)) goes on increasing with $\mathrm{T} 2$. The normalised entropy generation $\quad(\mathrm{Sg}, \mathrm{e} / \mathrm{Sg}, \mathrm{e}(\max ))$ attains its minimum value at temperature $\mathrm{T} 2=350 \mathrm{~K}$ while normalised entransy dissipation (Gdis, e/Gdis, e $(\max )$ ) has its maximum value at $\mathrm{T} 2=350 \mathrm{~K}$. The above observations can also be drawn by evaluating Equations (8), (31) and (39).Hence, the minimum entropy generation and the maximum entransy dissipation both correspond to the maximum output work when dumping the used stream into the environment is considered. 


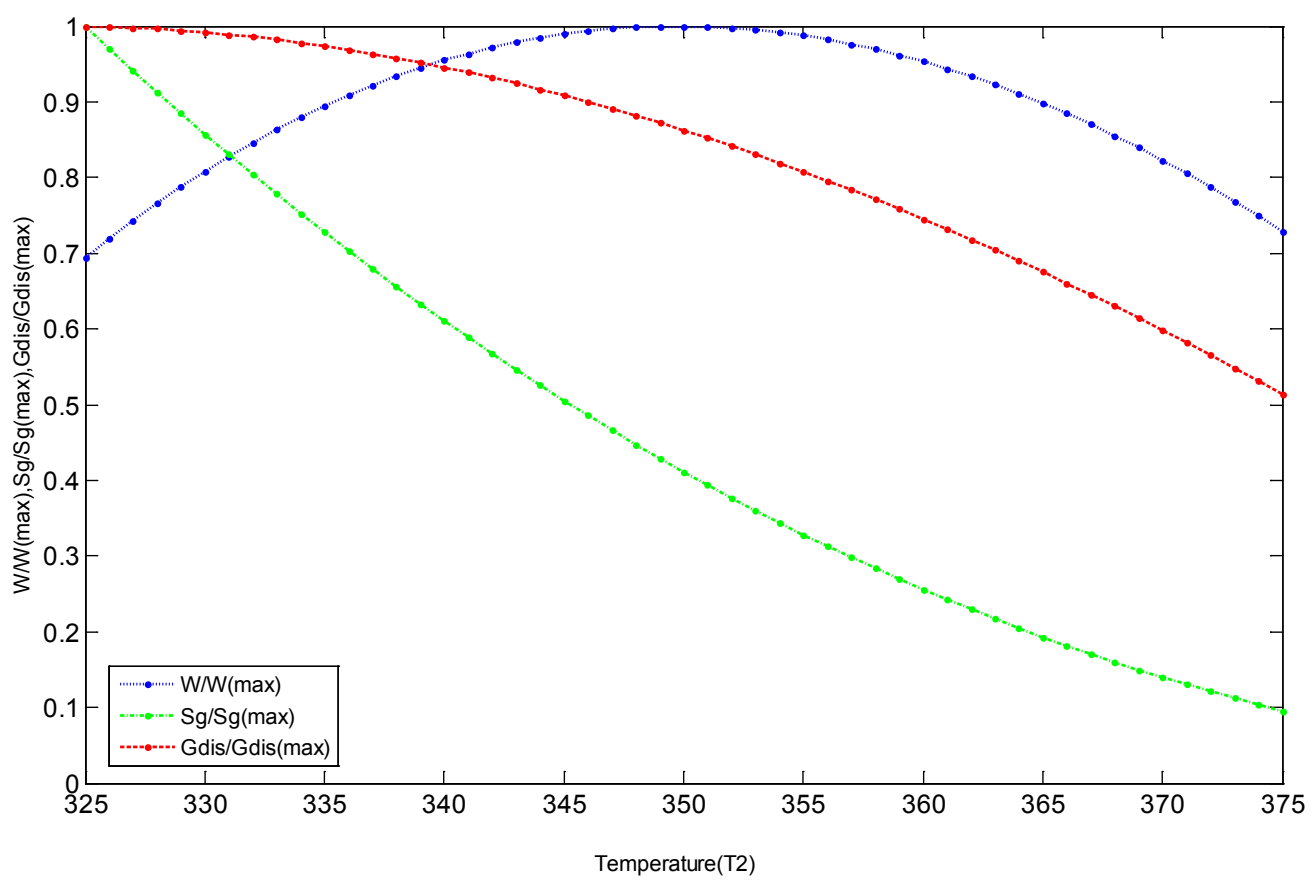

Figure 2. Variations of output work, the entropy generation and the entransy dissipation with $\boldsymbol{T}_{2}$ when the entropy generation and the entransy dissipation induced by dumping the used stream into the environment are not considered

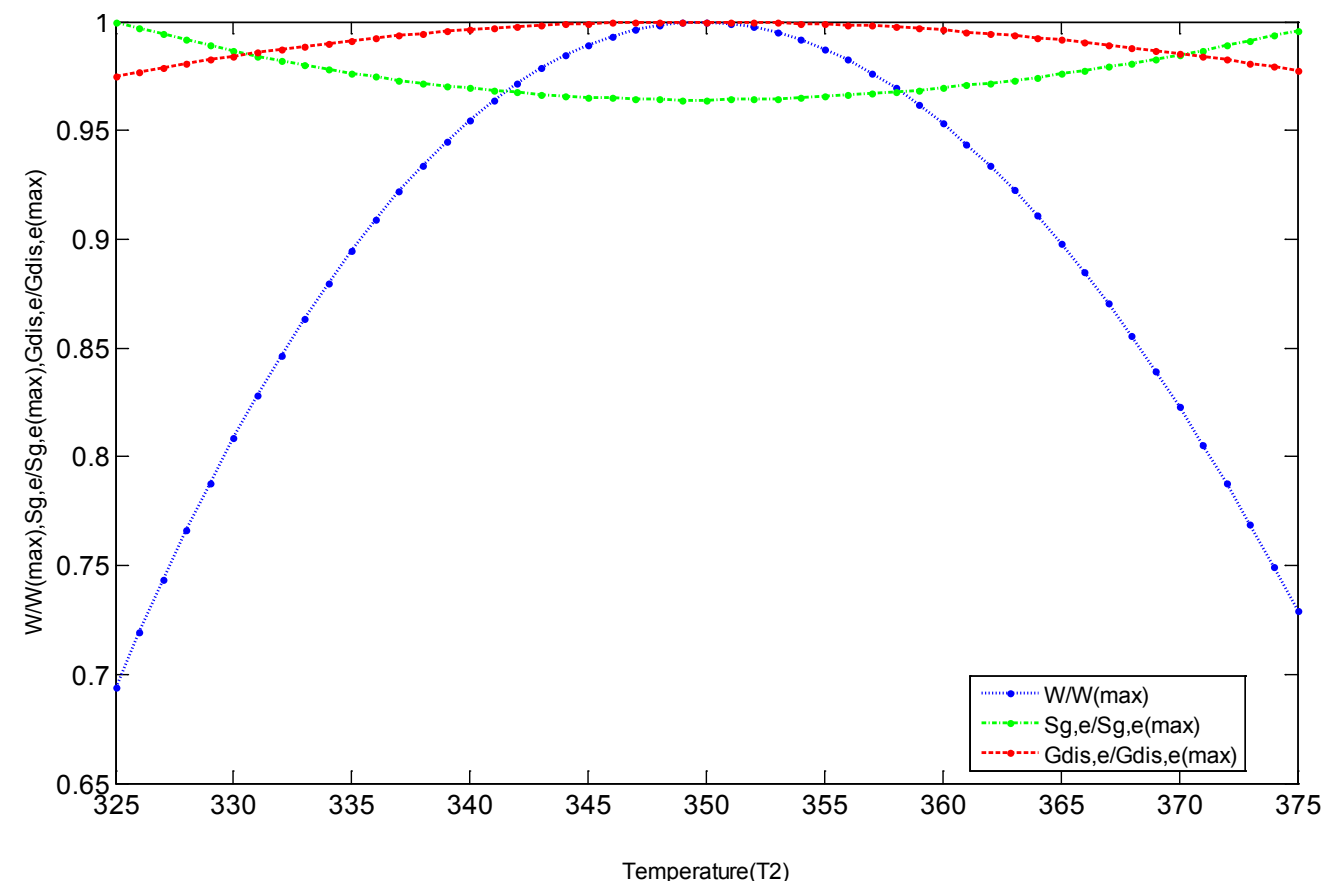

Figure 3. Variations of the output work, the entropy generation and the entransy dissipation with $\boldsymbol{T}_{\mathbf{2}}$ when the entropy generation and the entransy dissipation induced by dumping the used stream into the environment are considered.

Variations of the normalised output work, normalised entropy generation and normalised entransy dissipation with different values of heat capacity flow rate $\left(C_{P}\right)$, when the entropy generation and the entransy dissipation induced by dumping the used stream into the environment is not considered, are shown in Fig.4. As can be seen from the figure, values of normalised output work $\left(\mathrm{W} / \mathrm{W}_{(\max )}\right)$, normalised entropy generation $\left(\mathrm{S}_{\mathrm{g}} / \mathrm{S}_{\mathrm{g}(\max )}\right)$ and normalised entransy dissipation $\left(\mathrm{G}_{\mathrm{dis}} / \mathrm{G}_{\mathrm{dis}}\right.$ (max) go on increasing with $C_{\mathrm{P}}$ but attains their maximum values at different values $\mathrm{C}_{\mathrm{P}}$. The maximum value of normalised output work is at $C_{P}=1.7 \mathrm{~W} / \mathrm{K}$, maximum value of normalised entropy generation is at $C_{P}=3 \mathrm{~W} / \mathrm{K}$ and maximum value of normalised entransy dissipation is at $C_{P}=2.5 \mathrm{~W} / \mathrm{K}$. The above observations can also be drawn by evaluating Equations (8), (16) and (24). Hence, the minimum entropy generation and the maximum entransy dissipation both does not correspond to the maximum output work when dumping the used stream into the environment is not considered. 
Variations of the normalised output work, normalised entropy generation and normalised entransy dissipation with different values of heat capacity flow rate $\left(\mathrm{C}_{\mathrm{P}}\right)$, when the entropy generation and the entransy dissipation induced by dumping the used stream into the environment is considered, are shown in Fig.5. As can be seen from the figure, values of normalised output work (W/W (max) goes on increasing with $\mathrm{T}_{2}$ and attains its maximum value at $\mathrm{C}_{\mathrm{P}}=1.7 \mathrm{~W} / \mathrm{K}$. On the other hand, the normalised entropy generation $\left(\mathrm{S}_{\mathrm{g}, \mathrm{e}} / \mathrm{S}_{\mathrm{g}, \mathrm{e}(\max )}\right)$ attains its minimum value at temperature $\mathrm{C}_{\mathrm{P}}=1.7 \mathrm{~W} / \mathrm{K}$ while normalised entransy dissipation $\left(\mathrm{G}_{\mathrm{dis}, \mathrm{e}} / \mathrm{G}_{\mathrm{dis}, \mathrm{e}(\max )}\right)$ has its maximum value at $\mathrm{C}_{\mathrm{P}}=1.7 \mathrm{~W} / \mathrm{K}$. The above observations can also be drawn by evaluating Equations (8), (31) and (39).Hence, the minimum entropy generation and the maximum entransy dissipation both correspond to the maximum output work when dumping the used stream into the environment is considered.

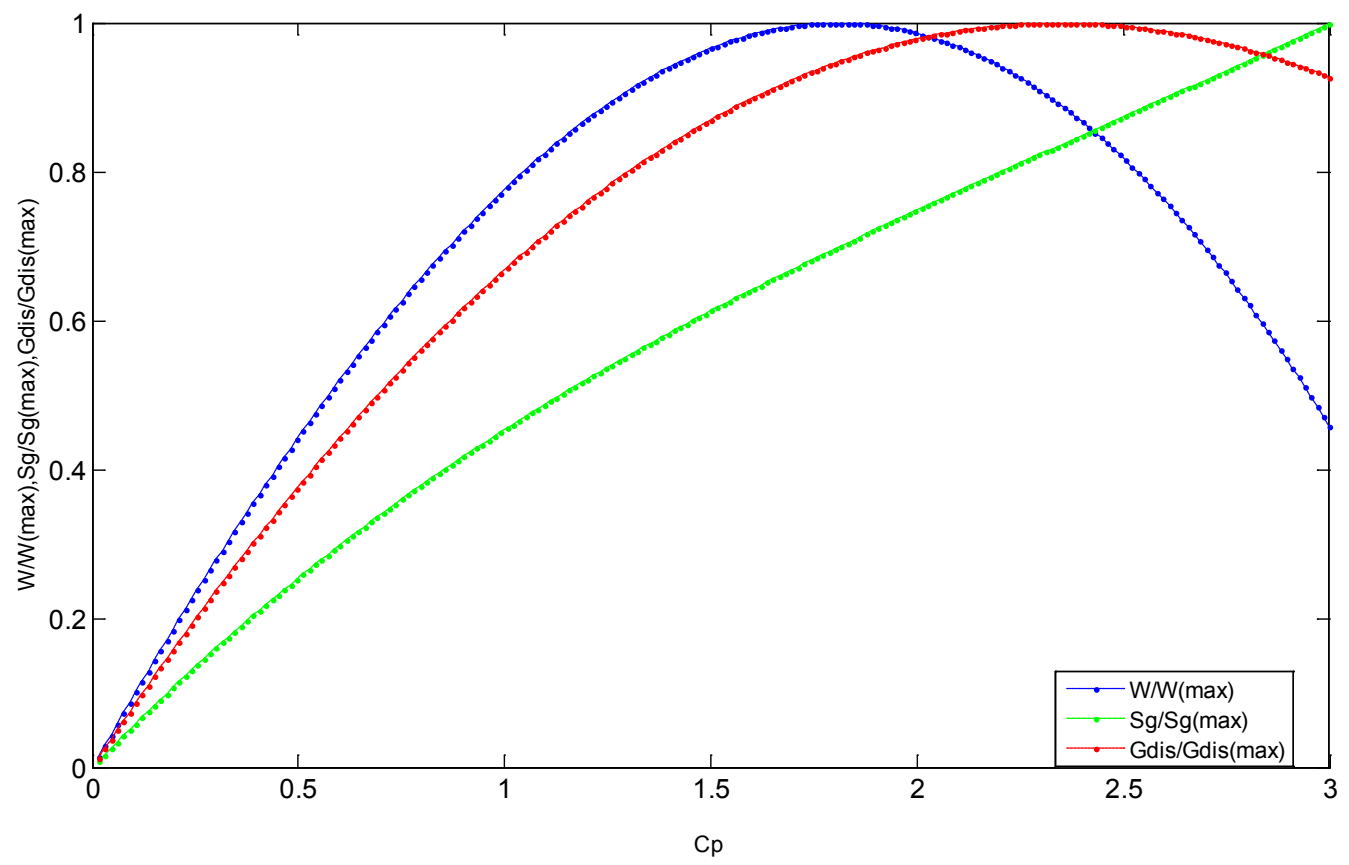

Figure 4. Variations of the output work, the entropy generation and the entransy dissipation with $\boldsymbol{C}_{\boldsymbol{P}}$ when the entropy generation and the entransy dissipation induced by dumping the used stream into the environment are not considered

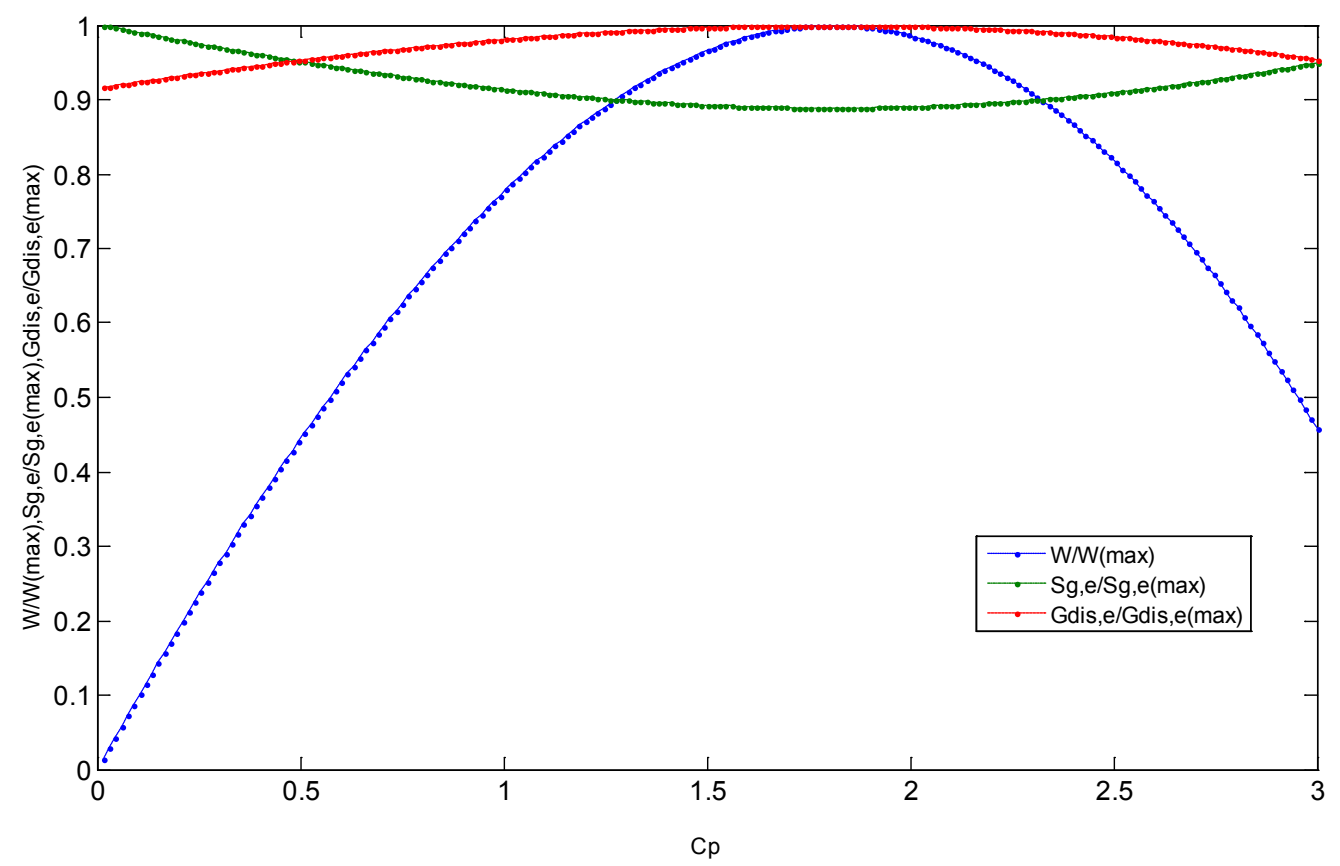

Figure 5. Variations of the output work, the entropy generation and the entransy dissipation with $\boldsymbol{C}_{\boldsymbol{P}}$ when the entropy generation and the entransy dissipation induced by dumping the used stream into the environment are considered 


\section{Conclusion}

In this paper, the entransy balance equation of thermodynamic processes is introduced for the first time in Atkinson cycle. For any thermodynamic process, it is found that some of the net entransy flow from the heat sources is dissipated during the heating and the cooling processes of the working fluid, while the rest is lost in the process of doing work. For the Atkinson cycle and the irreversible thermodynamic processes where the working fluid is heated by the streams with prescribed inlet temperatures and specific capacity flow rates, it is found that the maximum entransy dissipation corresponds to the maximum output work. Since entropy generation, being point function, is zero for reversible cycle hence, the concept of entransy dissipation could be used to describe the performance of thermodynamic processes. With the maximum principle of entransy dissipation and the minimum principle of entropy generation, the thermodynamic optimization design of the irreversible Atkinson cycle are analyzed and discussed. It is found that the operation parameters could be optimized to get the maximum output work by calculating the maximum entransy dissipation and the minimum entropy generation when the entropy generation and the entransy dissipation induced by dumping the used stream into the environment are considered.

\section{REFERENCES}

[1] Pulkrabek WW. Engineering Fundamentals of the Internal Combustion Engines, 2nd end. Prentice-Hall, 2004.

[2] Chen Q, Wang M, Pan N, and Guo ZY. Optimization principles for convective heat transfer. Energy 2009; 34:1199-1206.

[3] Bejan, Entropy Generation Minimization, CRC Press, Florida, 1996.

[4] Chen L, Wu C, Sun F. Finite-time thermodynamic optimization or entropy-generation minimization of energy Systems. J Non-Equil Thermod 1999; 24:327-59.

[5] Ge Y, Chen L, Sun F. Finite time thermodynamic modeling and analysis for an irreversible Atkinson cycle. Therm Sci 2010; 14:887-96.

[6] Lin JC, Hou SS. Influence of heat loss on the performance of an airstandard Atkinson cycle. Appl Energy 2007; 84:904-20.

[7] Prigogine, Introduction to Thermodynamics of Irreversible Processes, Wiley, New York, 1967.

[8] Bejan, Entropy Generation through Heat and Fluid Flow, Wiley, New York, 1982.
[9] Bejan A. Entropy generation minimization: the new thermodynamics of finite-size device and finite-time processes. J Appl Phys 1996; 79:1191-218.

[10] V. Bertola, E. Cafaro, A critical analysis of the minimum entropy production theorem and its application to heat and fluid flow, International Journal of Heat and Mass Transfer 51 (2008) 1907-1912.

[11] Bejan, Second-law analysis in heat transfer and thermal design, Adv. Heat Transfer 15 (1982) 1-58.

[12] Guo ZY, Zhu HY, Liang XG. Entransy-A physical quantity describing heat transfer ability. Int J Heat Mass Transfer 2007; 50: 2545-2556.

[13] X.T. Cheng, X.G. Liang, Z.Y. Guo, Entransy decrease principle of heat transfer in an isolated system, Chin. Sci. Bull. 56 (2011) 847-854.

[14] X.G. Liang, X.H. Xu, X.T. Cheng, Microscopic expression of entransy, Acta Phys. Sin 60 (2011) 060-512.

[15] H.Y. Zhu, Z.J. Chen, Z.Y. Guo, Thermal electric analogy experimental research for the extreme principle of entransy dissipation (In Chinese), Prog. Nat. Sci. 17 (2007) 1692-1698.

[16] Z.H. Xie, L.G. Chen, F.R. Sun, Constructal optimization on T-shaped cavity based on entransy dissipation minimization, Chin. Sci. Bull. 54 (2009) 4418-4427.

[17] Q.H. Xiao, L.G. Chen, F.R. Sun, Constructal entransy dissipation rate minimization for "disc-to-point" heat conduction, Chin. Sci. Bull. 56 (2011) 102-112.

[18] Q. Chen, J.X. Ren, Generalized thermal resistance for convective heat transfer and its relation to entransy dissipation, Chin. Sci. Bull. 53 (2008) 3753-3761.

[19] Q. Chen, M. Wang, N. Pan, et al., Optimization principles for convective heat transfer, Energy 34 (2009) 1199-1206.

[20] J. Wu, X.G. Cheng, J.A. Meng, et al., Potential capacity dissipation extreme and entropy generation minimization in laminar convective heat transfer (In Chinese), J. Eng. Thermophys 27 (2006) 100-102.

[21] J. Wu, X.G. Liang, Application of entransy dissipation extreme principle in radiative heat transfer optimization, Sci. China Ser. E-Tech. Sci. 51 (2008) 1306-1314.

[22] X.T. Cheng, X.G. Liang, Entransy flux of thermal radiation and its application to enclosures with opaque surfaces, Int. J. Heat Mass Transfer 54 (2011) 269-278.

[23] X.B. Liu, M. Wang, J. Meng, E. Ben-Naim, et al., Minimum entransy dissipation principle for the optimization of transport networks, Int. J. Nonlin. Sci. Num 11 (2010) 113-120.

[24] Chen Q, Wu J, Wang MR, Pan N, Guo ZY. A comparison of optimization theories for energy conservation in heat exchanger groups. Chin Sci Bull 2010; 56: 449-454.

[25] X.T. Cheng, X.G. Liang, Entransy loss in thermodynamic processes and its application, Energy 2012 DOI 10.1016/j. energy. 2012.04.054. 